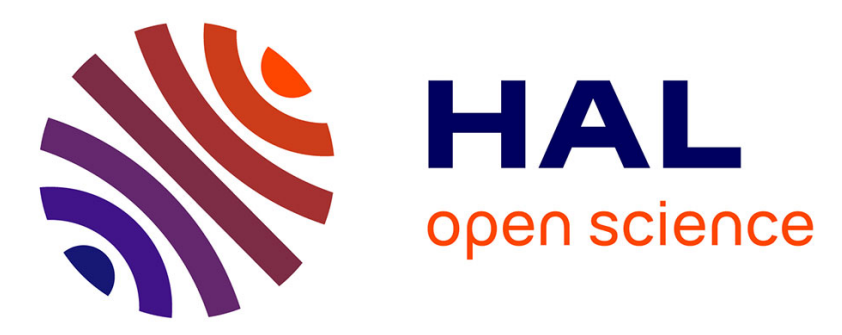

\title{
Characterization of defects situated in a fresco by stimulated infrared thermography
}

\author{
J.C. Candoré, J.L. Bodnar, V. Detalle, P. Grossel
}

\section{To cite this version:}

J.C. Candoré, J.L. Bodnar, V. Detalle, P. Grossel. Characterization of defects situated in a fresco by stimulated infrared thermography. European Physical Journal: Applied Physics, 2012, 57 (1), 10.1051/epjap/2011110243 . hal-00758053

\section{HAL Id: hal-00758053 https://hal.science/hal-00758053}

Submitted on 28 Nov 2012

HAL is a multi-disciplinary open access archive for the deposit and dissemination of scientific research documents, whether they are published or not. The documents may come from teaching and research institutions in France or abroad, or from public or private research centers.
L'archive ouverte pluridisciplinaire HAL, est destinée au dépôt et à la diffusion de documents scientifiques de niveau recherche, publiés ou non, émanant des établissements d'enseignement et de recherche français ou étrangers, des laboratoires publics ou privés. 


\title{
Characterization of defects situated in a fresco by stimulated infrared thermography
}

\author{
J.C. Candoré*, J.L. Bodnar*, V. Detalle** et P. Grossel* \\ * GRESPI/ ECATHERM, UFR Sciences Exactes et Naturelles, BP 1039, 51687 Reims cedex 02 \\ ** Laboratoire de Recherche des Monuments Historiques, 29 avenue du Paris, 77420 Champs sur \\ Marne
}

\begin{abstract}
The objective of this work is to approach the possibilities of stimulated infrared thermography in dimensional characterization of defects situated in mural paintings. Towards this end, we have proceeded in two stages. Initially, we have developed, with the help of a point source photothermal analysis, an in situ measurement of the longitudinal thermal diffusivity parameter. Then, we have proceeded to the characterization of the depth of the studied defect, by means of a wide photothermal analysis and of a confrontation between theory and experiment. In this article, we present these two measurements techniques and show that the approach allows a good estimation of the depth of an inclusion of plastazote in a copy of the "Saint Christophe" of the "Campana" collection of the "Louvre Museum".
\end{abstract}

\section{Introduction}

Detachments and air voids are very frequent defects in mural paintings. They are the more dangerous as they are invisible on the surface and can provoke the failure of whole pieces of composition. The traditional technique used by the restorer to detect detachments is acoustic analysis. It consists of analyzing the surface of the work of art by tapping it slightly with fingers. To estimate the response of the studied sample, the restorer uses hearing and touch: while he taps the surface with a hand, the other hand remains pressed to the surface of the work of art to determine the intensity and the distance of the induced vibrations. This method requires no particular equipment and remains simple to implement. However the quality of the diagnosis depends on the ability and experience of the restorer. This method is always subjective and limited in the information which it can provide. The depth of the defect and its thickness, not really accessible by acoustic analysis, are useful information which would allow the restorer not only to better estimate the real fragility of the painting, but also to implement means more adapted for the consolidation. Besides, the acoustic analysis requires a prolonged and energetic physical contact with the surface which can be dangerous if the painting is fragile. The coat, itself, if it is very fine, can break down easily if the analysis is too aggressive. Finally, it is necessary to note that, in the cases of decorations covering all the walls of a building, acoustic examination is very laborious and very slow to implement [1].

Stimulated infrared thermography is already implemented to detect and characterize defects (cracks, inclusions, etc) in various types of materials. It then seemed to us to be usable in the field of art restoration. Indeed, the infrared method is fast, without contact, objective and allows the analysis of wide surfaces [2-8].

In this work, we study the possibilities of this method to help the work of art restoration. We focus on the possibilities of the method to allow geometrical characterization of defects. To measure the depth of the defect, we propose using a pulsed photothermal analysis associated to theory / experiment adjustment. To feed the theoretical adjustment model, it is necessary to know the real thermal diffusivity of the studied work of art. In our case, we chose to measure the longitudinal part of this thermophysical parameter. To measure depth, we work 
in two stages. Initially, we proceed to an in situ and local measurement of the thermal diffusivity parameter. Then, we determinate the depth by a flash photothermal analysis subject to theory / experiment adjustment.

In this paper, we present the principles of these two techniques of measurements and the experimental results obtained.

Initially, we present the theoretical principle of in situ measurement of longitudinal thermal diffusivity retained for the study.

We then present a thermal diffusivity measurement carried out on an academic plaster sample and on a copy of the "Saint Christophe" of the "Campana" collection of the "Louvre Museum".

We present in the third stage, the thermal model leading to the depth measurement.

We show finally, that the method allows a good estimation of the depth of a plastazote inclusion located in the studied fresco.

\section{Principle of the longitudinal thermal diffusivity measurement retained for the study}

The general principle of longitudinal thermal diffusivity measurement by front face photothermal thermography, is the following: an anisotropic sample is submitted on its front face to an excitation temporally close to a Dirac function $\delta(t)$ and of spatial shape $f(x, y)$. We measure then the field of temperature on the front face with an infrared thermography camera. From the temporal evolution of this field of temperature, we determinate by means of a mathematical post-treatment, the values of the material thermal diffusivity according to its directions of anisotropy.

Let us examine in detail this mathematical post-treatment on which is based this technique of measure. $\lambda_{x}, \lambda_{y}$ and $\lambda_{z}$ are the thermal conductivities of the studied sample. These thermal conductivities are assumed constant in time and depend on the temperature (hypotheses of short analyses and weak temperature variations). $\rho$ and $c_{p}$ are the density and the calorific capacity of the sample. The thermal diffusivities of the studied sample are $a_{x}, a_{y}$ and $a_{z}$. The exchange coefficients of the front and the back face of the sample are $h_{0}$ and $h_{e}$. e is the thickness of the material. This thickness is assumed to be very small compared to the width of the sample. This allows us to neglect the convecto-radiative losses on the lateral sides of the sample. Finally, the sample is initially considered in thermal balance with its environment (figure 1).

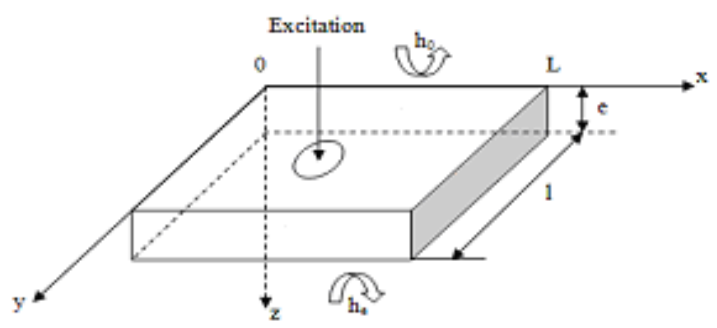

Figure 1: The boundary conditions

The mathematical translation of these hypothesis leads to the following differential system

$$
\lambda_{x}\left(\partial^{2} T / \partial x^{2}\right)+\lambda_{y}\left(\partial^{2} T / \partial y^{2}\right)+\lambda_{z}\left(\partial^{2} T / \partial z^{2}\right)=\rho c(\partial T / \partial t)
$$

$$
\begin{aligned}
& \mathrm{z}=0 \\
& \mathrm{z}=\mathrm{e}
\end{aligned}
$$$$
\lambda_{z}(\partial T / \partial z)_{z=0}=h_{0}\left(T(z=0)-T_{e x t}\right)-f(x, y) \delta(t)
$$$$
\lambda_{z}(\partial T / \partial z)_{z=0}=-h_{e}\left(T(z=e)-T_{e x t}\right)
$$ 


$$
\begin{array}{ll}
\mathrm{x}=0 \text { et } \mathrm{x}=\mathrm{L}_{\mathrm{x}}, & \partial T / \partial x=0 \\
\mathrm{y}=0 \text { et } \mathrm{y}=\mathrm{L}_{\mathrm{y}}, & \partial T / \partial y=0 \\
\mathrm{t}=0, & \mathrm{~T}=\mathrm{T}_{\text {ext }}
\end{array}
$$

To solve this differential system, we choose to implement three integral transforms: a time Laplace transform associated with a cosine Fourier transform in $\mathrm{x}$ and $\mathrm{y}$ coordinates:

$$
\theta\left(\alpha_{n}, \beta_{m}, z, p\right)=\int_{t=0}^{\infty} \int_{y=0}^{L_{y}} \int_{x=0}^{L_{x}} T(x, y, z, t) \cos \left(\alpha_{n} x\right) \cos \left(\beta_{m} y\right) \exp (-p t) d x d y d t
$$

with:

$$
\begin{aligned}
\alpha_{\mathrm{n}} & =\mathrm{n} \pi / \mathrm{L}_{\mathrm{x}} \\
\beta_{\mathrm{m}} & =\mathrm{m} \pi / \mathrm{L}_{\mathrm{y}}
\end{aligned}
$$

We apply these integral transforms to the preceding differential system. The differential equation obtained in the transformed space only depends on the $\mathrm{z}$ coordinate. It can be easily solved by the thermal quadrupoles method [9]. We obtain:

$$
\Theta\left(\alpha_{n}, \beta_{m}, z=0, p\right)=\frac{F\left(\alpha_{n}, \beta_{m}\right)\left(\operatorname{ch}\left(\gamma_{n, m} e\right)+h_{e} \operatorname{sh}\left(\gamma_{n, m} e\right) /\left(\lambda_{z} \gamma_{n, m}\right)\right)}{\lambda_{z} \gamma_{n, m} \operatorname{sh}\left(\gamma_{n, m} e\right)+\left(h_{0}+h_{e}\right) \operatorname{ch}\left(\gamma_{n, m} e\right)+h_{0} h_{e} \operatorname{sh}\left(\gamma_{n, m} e\right) /\left(\lambda_{z} \gamma_{n, m}\right)}
$$

with :

$$
\gamma_{n, m}=\sqrt{p / a_{z}+\left(\lambda_{x} / \lambda_{z}\right) \alpha_{n}^{2}+\left(\lambda_{y} / \lambda_{z}\right) \beta_{m}^{2}}
$$

$\mathrm{F}\left(\alpha_{\mathrm{n}}, \beta_{\mathrm{m}}\right)$ is the Laplace Fourier transform of the exciting flux

By taking the inverse Laplace transform of the temperature, we obtain:

$$
\ln \left(\frac{\theta\left(\alpha_{n}, \beta_{m}, z=0, t\right)}{\theta(0,0, z=0, t)}\right)=\ln \left(\frac{F\left(\alpha_{n}, \beta_{m}\right)}{(F(0,0)}\right)-\left(a_{x} \alpha_{n}{ }^{2} t+a_{y} \beta_{m}{ }^{2} t\right)
$$

We notice that the longitudinal thermal diffusivity can be deduced from the slope of the curve representing the ratio of the logarithm of Fourier coefficient drawn versus the time.

$$
a=\left(\text { slope of curve } * \text { dimension of analyzed area }{ }^{2}\right) /\left(\text { Fourier }_{\text {order }}{ }^{2} * \pi^{2}\right)
$$

\section{The experimental device implemented for thermal diffusivity measurement}

The experimental device implemented for the study is composed of excitation optics, infrared detection optics and, finally, computing of the instrumentation. The source of excitation used is a laser diode emitting at $810 \mathrm{~nm}$. It is associated with optics of collimation and focusing. The optics of infrared acquisition is a "long waves" camera using bolometer 
detectors. It works in a macro mode to obtain sufficient spatial resolution. This camera is perpendicularly placed at the sample. The distance between the twice is about $5 \mathrm{~cm}$. Because of the dimensions of the infrared camera, the laser beam strikes the sample at an angle. The shape of the laser spot is then slightly elliptic. The power of the laser diode is about $2 \mathrm{~W}$. The duration of the excitation is about $20 \mathrm{~ms}$. The acquisition frequency of the infrared camera is $50 \mathrm{~Hz}$ (figure 2).

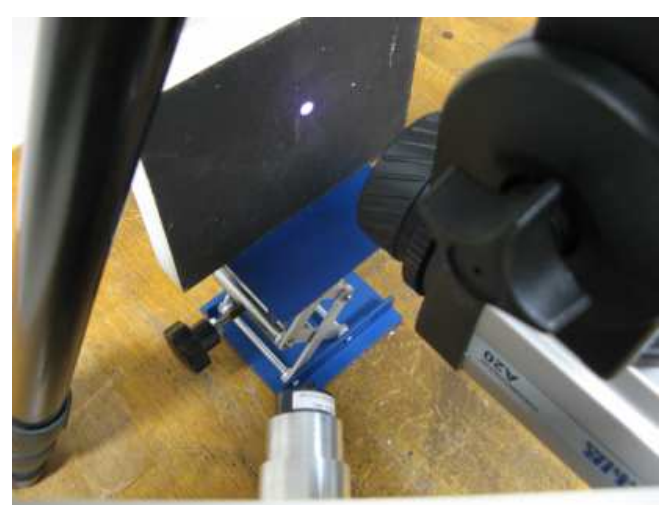

Figure 2: The experimental device implemented for thermal diffusivity measurement

\section{Experimental thermal diffusivity measurement of an academic sample}

The first sample we analyzed experimentally in this study is an academic sample : a block of plaster. The geometrical dimensions are $12 \mathrm{~cm}$ wide, $15 \mathrm{~cm}$ long and $2.2 \mathrm{~cm}$ thick. It is covered with a thin black coating of paint on the analyzed side, to simulate the presence of a pictorial layer. Initially, we want to determine exactly the thermal diffusivity of this sample. We used the reference flash diffusivimeter from LEMTA in Nancy (France) [10,11]. For this study, we cut a part of the sample and manufactured it to reduce its thickness to $6.05 \mathrm{~mm}$. This thickness is then compatible to a study with this reference diffusivimeter. The duration of the excitation is $5 \mathrm{~ms}$ (It is the standard value of this diffusivimeter). The temperature measurement is made at the rear face of the sample, by a semi conductor thermocouple of type tellurium of bismuth. To obtain the thermal diffusivity parameter, we have used three standards modes of analysis of the thermal signal obtained: the partial-times method, the temporal moment's method and an adjustment theory / experiment. The values of thermal diffusivity obtained are: $3.4910^{-7} \mathrm{~m}^{2}$ by means of the method of partial-times, $3.5310^{-7} \mathrm{~m}^{2} /$, by means of the method of temporal moments and $3.4910^{-7} \mathrm{~m}^{2} /$ by means of an adjustment theory / experiment (figure 3). 


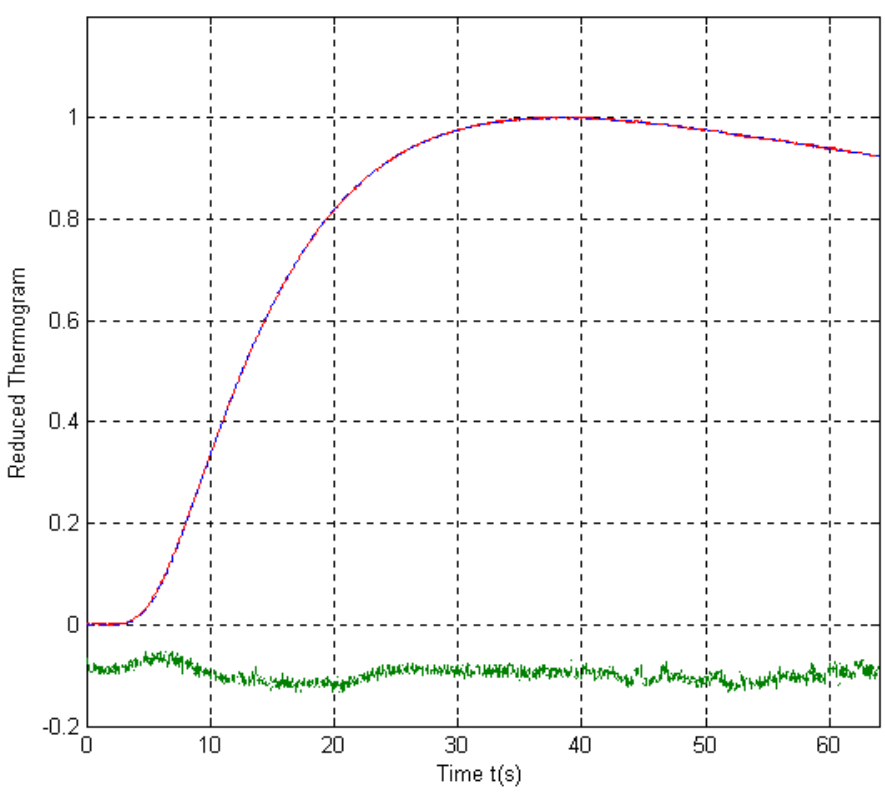

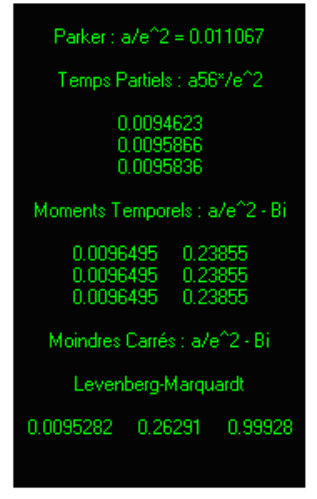

Diffusivité Thermique

épaisseur : $e=6.05 \mathrm{~mm}$ Parker : a $=4.0508 \mathrm{e}-007 \mathrm{~m}^{2} / \mathrm{s}$ P.Time : $a=3.4934 \mathrm{e}-007 \mathrm{~m}^{2} / \mathrm{s}$ Moments : $a=3.532 \mathrm{e}-007 \mathrm{~m}^{2} / \mathrm{s}$
0. L.S. : $a=3.4875 \mathrm{e}-007 \mathrm{~m}^{2} / \mathrm{s}$

Figure 3: Measurement of the thermal diffusivity of the academic sample by the standards methods

Next, we analyzed part of the uncut sample by a local front face photothermal method. As mentioned, we lighted the studied sample with a laser spot. The dimension of the light on the surface is about $1 \mathrm{~mm}^{2}$. The laser power is about 2 Watts. The excitation duration is $20 \mathrm{~ms}$. This heating was filmed in a synchronous way with excitation by an infrared thermography camera, a Flir A20. This camera is implemented in a macro mode to have enough spatial resolution. On figure 4, we present four representative infrared images obtained. It is the temporal evolution of the photothermal signature of the laser spot. This figure shows clearly the thermal signature becomes more spread and less intense with time.
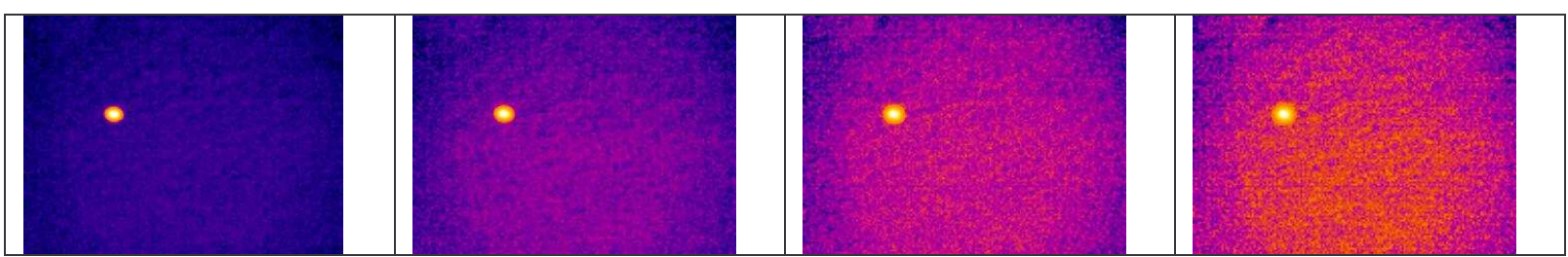

Figure 4: Temporal evolution of the infrared signature of the laser spot

In accord with the theory, we took cosine Fourier transforms of these various images. We then calculated, for each of them, the logarithm of the ratio of the order 2 Fourier coefficients divided by order 0 Fourier coefficients. Figure 5 shows the result obtained. It shows, as predicted by the theory, a straight line with a negative slope. It is equal, in this case to $2.558 \mathrm{~s}^{-1}$. 


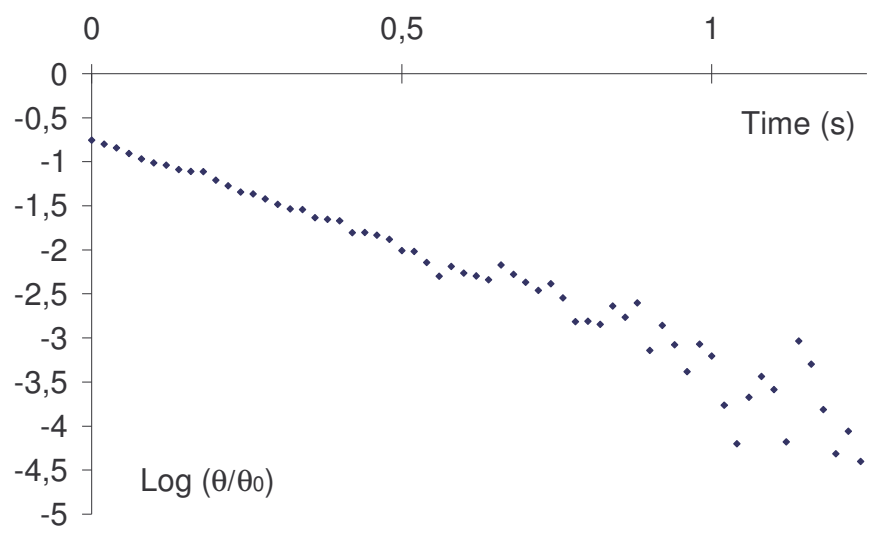

Figure 5: Temporal evolution of the logarithm of the ratio of the order 2 Fourier coefficients divided by order 0 Fourier coefficients.

Finally, we have calibrated spatially our experimental device. For this purpose, we have placed a calibrated surface on the studied object. We have then deduced from the infrared image obtained, the spatial dimension seen by pixel. We have found a value of $116 \mu \mathrm{m}$. To obtain the thermal diffusivity, we have used formula 5 . We obtained a value of $3.4910^{-7} \mathrm{~m}^{2} \mathrm{~s}^{-1}$. This value is very close to those obtained with the standard flash method. It seems to show the possibilities of the local photothermal method for the in situ thermal diffusivity measurement. .

\section{Thermal diffusivity measurement of a mural painting}

The results obtained on the academic sample being positive, we have in the second stage, measured the thermal diffusivity of a real mural painting. It is a partial copy of the "Saint Christophe" of the "Campana" collection of the "Louvre Museum" (France). This fresco was made by Gabriela Szatanik, a professional restorer. This mural painting is realized in a mixture of lime and plaster covered with the pictorial layer. This work of art contains 5 inclusions of plastazote situated at different depths (figure 6)
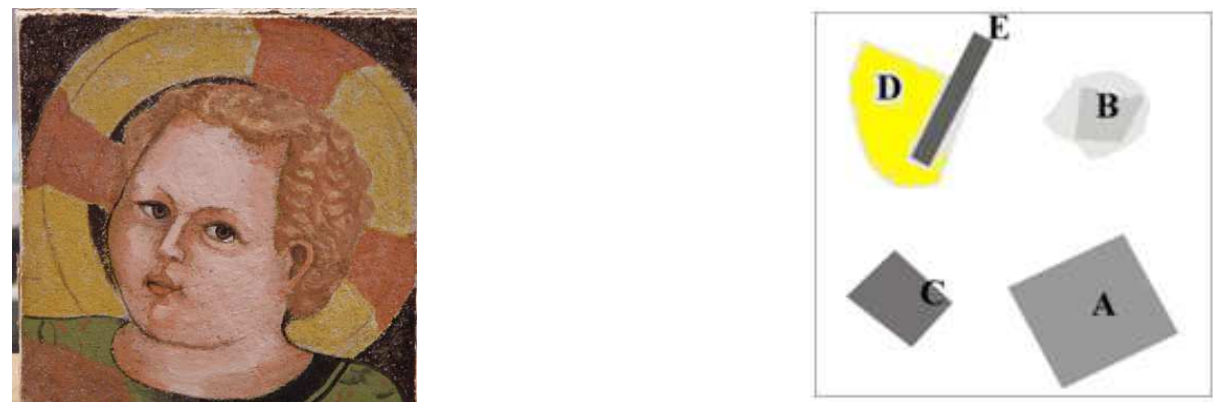

Figure 6: The studied mural painting and location of inclusions of plastazote

To measure the thermal diffusivity of this fresco, we proceeded as above. Initially, we lighted the work of art with a laser spot. The power delivered is 2 watt and the duration of the excitation is $20 \mathrm{~ms}$. We have observed then the photothermal response with an infrared thermography camera equipped with a macro lens. The frequency of acquisition is $50 \mathrm{~Hz}$. The order of the Fourier analysis is 2 . The area analyzed is the left eye of the Infant Jesus. It is an area without defect (figure 7). 


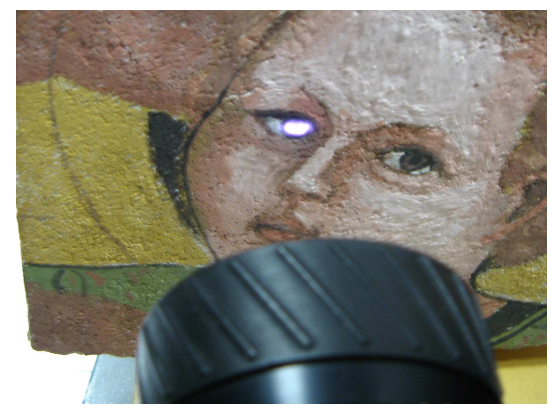

Figure 7: Thermal diffusivity measurement of the partial copy of "Saint Christophe" of the "Louvre Museum"

On figure 8, we present the temporal evolution of the ratio of the Fourier coefficients. The slope of this curve is about $2.6 \mathrm{~s}^{-1}$.

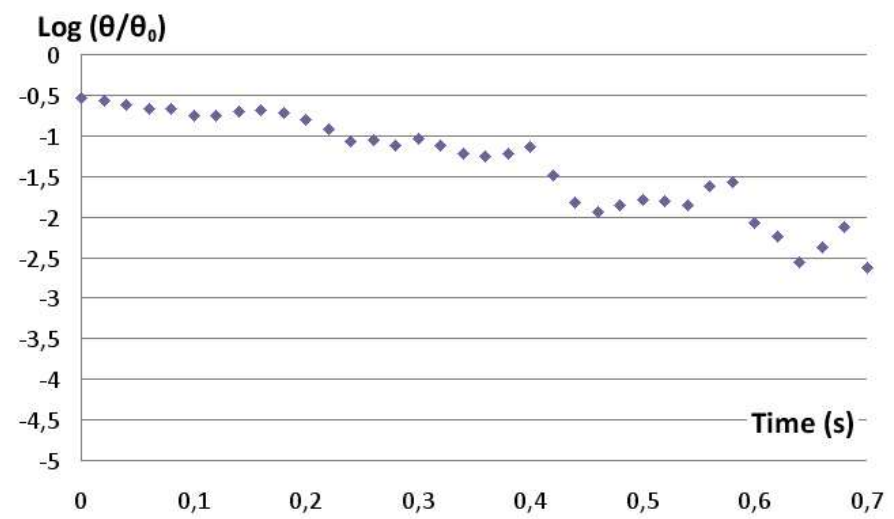

Figure 8: Temporal evolution the logarithm of the ratio of the order 2

Fourier coefficients divide by order 0 Fourier coefficients.

Finally, we calibrated spatially our experimental device. For that purpose, we placed a reference surface on the work of art. We deduced from the obtained infrared image a spatial dimension of the pixel equal to $147 \mu \mathrm{m}$. We used finally the formula 5 to determine the longitudinal value of the thermal diffusivity of the work of art. We found a value equal to $5.1310^{-7} \mathrm{~m}^{2} \mathrm{~s}^{-1}$.

\section{The thermal model developed to measure the depth of the defect}

After the determination of the thermal diffusivity of the mural painting studied, we want now to measure the depth of the plastazote inclusions number D (Figure 6). We want to work with a theory / experiment adjustment.

Absolutely, the study of an inclusion in a sample leads to the use of a 3 layers model, the intermediate layer representing the defect. In our case, the thickness of this internal defect can be of several millimeters of air. It constitutes, from a thermal point of view, a relatively important thermal barrier. So during the photothermal analysis, the main part of the thermal phenomena is confined in the layer of material situated between the front face of the studied sample and the defect. We chose then to use for our study only a mono layer thermal model. This choice presents different advantages. The model is simple to implement. It asks for less input parameters and is fast to solve. 
The model developed for the study considers, then, a mono - dimensional, homogeneous and isotropic sample. This sample is excited on its front face by a Dirac function. Convectoradiative losses are taken into account on its front and back faces (figure 9).

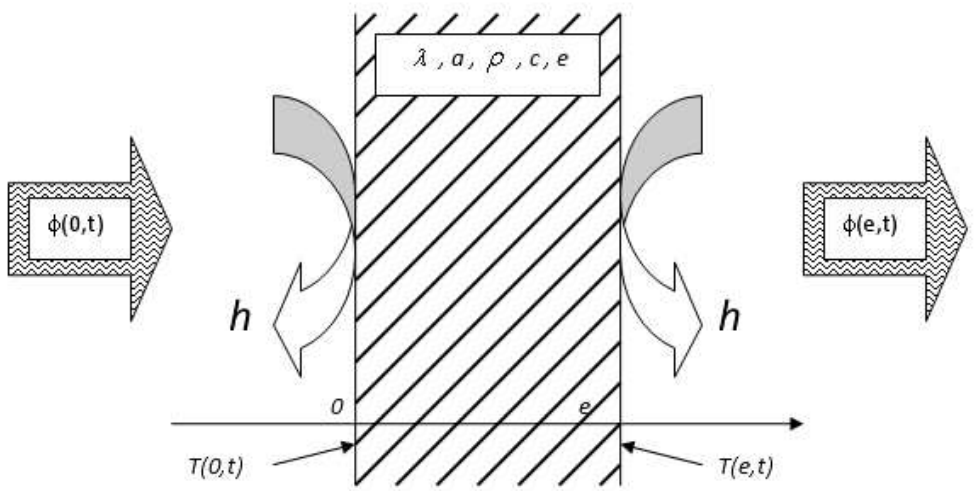

Figure 9: The thermal model used to measure the depth of the defect

To solve the heat equation, we used the thermal quadrupoles method (figure 10). It lead to the plan presented in figure 10 .

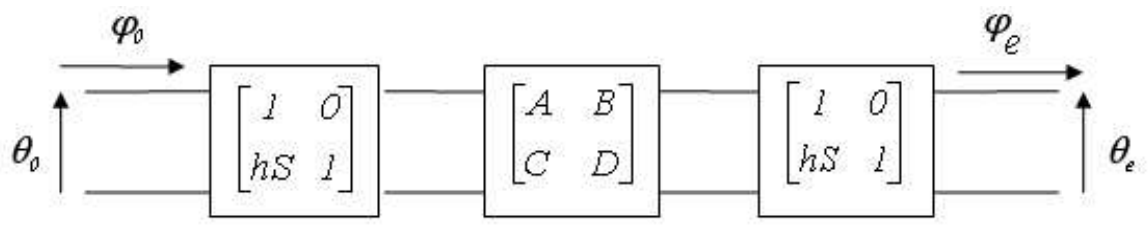

Figure 10: The thermal quadrupoles model developed for the study

This plan can be written in a matrix form:

$$
\left[\begin{array}{l}
\theta_{0}(p) \\
\varphi_{0}(p)
\end{array}\right]=\left[\begin{array}{cc}
1 & 0 \\
h S & 1
\end{array}\right]\left[\begin{array}{cc}
A & B \\
C & D
\end{array}\right]\left[\begin{array}{cc}
1 & 0 \\
h S & 1
\end{array}\right]\left[\begin{array}{l}
\theta_{e}(p) \\
\varphi_{e}(p)
\end{array}\right]
$$

As the input and output heat flows are all null except for the contribution of the flash, the development of this matrix product, give the Laplace transform of the front face:

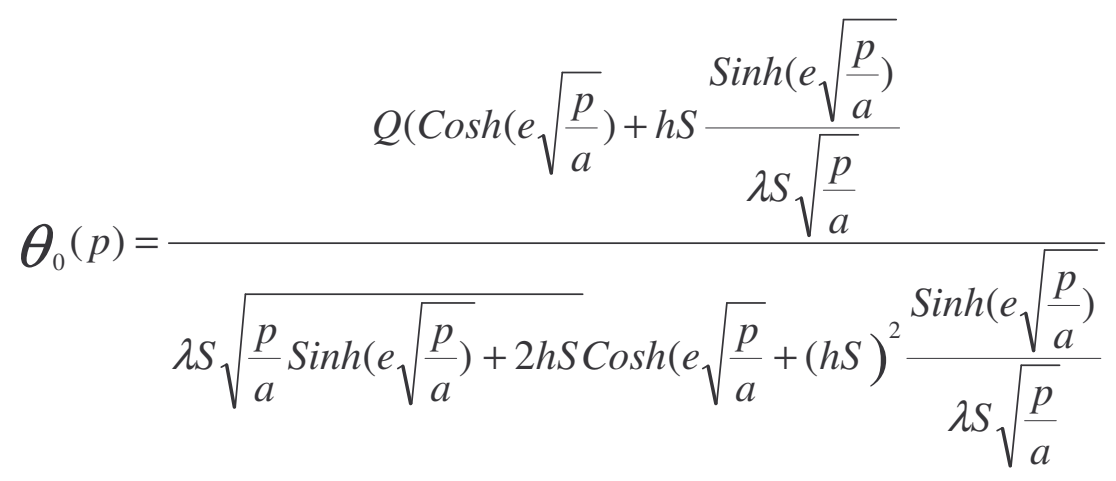

Finally, to return to the temporal space, we used the numerical method of Stefest. 


\section{The experimental device implemented for the depth of defect measurement}

The experimental device implemented for the depth of defect measurement is based on the same principle as the previous one. It contains excitation optics, an infrared optical detection chain and finally a computing of the instrumentation. Here, the source of excitation is two halogen lamps. It permits a wide excitation of the sample. The optical detection chain is composed of an infra-red thermography camera equipped of a $45^{\circ}$ lens. It is an A20 FLIR System camera. (Figure 11).

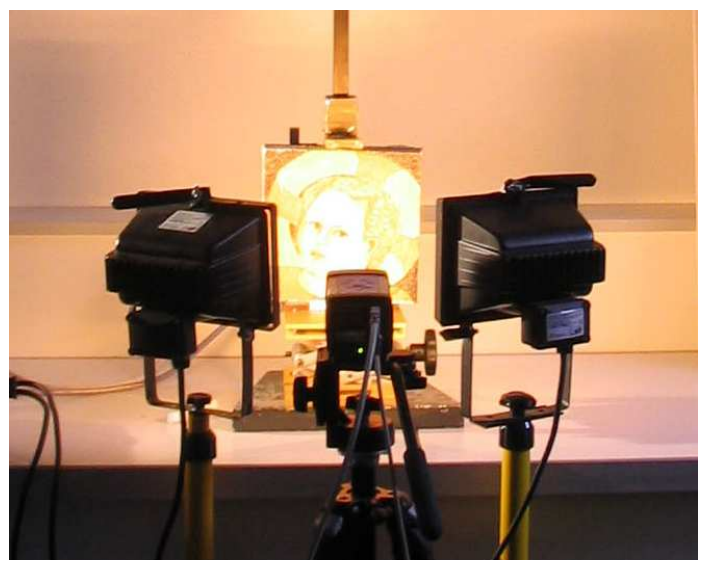

Figure 11: The experimental device implemented for depth measurement of the defect

\section{Depth estimation of the $D$ defect of the fresco}

In the last part of our work, we tried to determinate the depth of the defect D (figure 6) present in the copy of the "Saint Christophe". This plastazote inclusion is situated by construction in a depth of about $3 \mathrm{~mm}$. The experimental procedure used is the following. We lighted at first all the surface of the fresco. The type of the excitation is a pulse one. The duration of the excitation is 10 seconds. The power of the excitation is $2 * 500$ watts. In a second time we have extracted from the infrared film, the temporal temperature profile, of the area located directly above the $\mathrm{D}$ defect.

We then proceeded to a theory / experience adjustment. The inverse method used is the Levenberg Marquardt one. The thermal diffusivity taken into account for this adjustment is $5.1310^{-7} \mathrm{~m}^{2} \mathrm{~s}^{-1}$. This is the value measured previously. An example of adjustment between theory and experience is presented on the Figure 12. It shows, for the depth estimated as $2.91 \mathrm{~mm}$, that the theoretical and experimental curves are close and we have the minimum least square criteria. This value is very close to the reference value of $3 \mathrm{~mm}$. This result shows the feasibility of the method. 


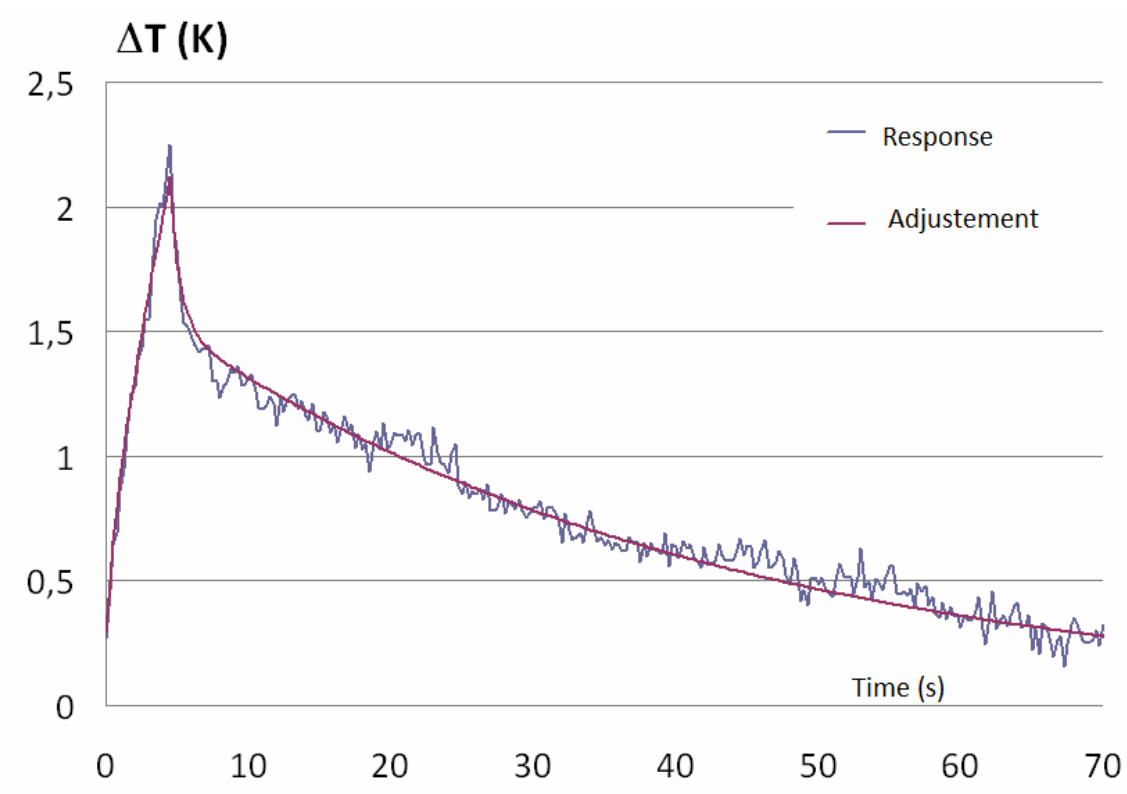

Figure 12: Adjustment between theory and experience

\section{Conclusions}

In this work, we approached the possibilities of stimulated infrared thermography in dimensional characterization of defects situated in mural paintings. Towards this end, we have proceeded in two stages. Initially, we developed, with the help of a point source photothermal analysis, an in situ measurement of the longitudinal thermal diffusivity parameter. Then, we proceeded to the characterization of the depth of the studied defect, by means of a wide photothermal analysis and of a confrontation between theory and experiment.

The experimental results obtained during the study of the "Saint Christophe" of the "Louvre Museum", show on the one hand the feasibility of the method. They thus validate the followed procedure. They show in addition that the theoretical assumptions selected for the study, are acceptable. They show finally that the experimental device used, wanted simple and easily transportable for in situ analysis, seems adapted to a quantitative measurement.

These results are encouraging. They ask now to be confirmed and generalized, for example in the case of in situ analysis. Studies going to this direction are in progress.

\section{References}

[1] G. Szatanik, Etude et restauration d'une peinture murale représentant Saint Christophe (collection Campana, Louvre Museum), mémoire de fin d'études, INP- département des restaurateurs, 2004.

[2] E. Grinzato, P.G. Bison, S. Marinetti, V. Vavilov, : Activ thermal testing of delaminations in frescoes' plaster, 4th International Conference on Non-destructive Testing of Works of Art, Berlin,1994, p. 357-367

[3] G. Schirripa Spagnolo, G. Guattari, E. Grinzato : Frescoes Diagnostics by electro-optic holography and infrared thermography, 6th World Conference on NDT and Microanalysis in Diagnostics and Conservation of Cultural and Environnemental Heritage, Rome, 1999, p. 385-398. 
[4] S. G. Tavares,A. Agnani, E. Esposito, M. Feligiotti, S. Rocchi , R. M. de Andrade : Comparative study between infrared thermography and laser Doppler vibrometry applied to frescoes diagnostic Proceeding of the QIRT2006 congress, Padoue, 2-4 July 2006 Italie

[5] Jean Charles Candoré, Gabriela Szatanik, J.L Bodnar, Vincent Detalle, Philippe Grossel : Infra-red photothermal thermography: A tool of assistance for the restoration of murals paintings? Actes du congrès QIRT2006, Padoue, Italie

[6] Jean Charles Candoré, J.L Bodnar, Vincent Detalle, Philippe Grossel : Non destructive testing of works of art by stimulated infrared thermography, procceding de qirt 2008, 2-3 juillet 2008, Cracovie, Pologne.

[7] J.C. Candoré, J.L Bodnar, V. Detalle, P. Grossel : Non destructive testing of mural paintings, in situ, by infrared photothermal radiometry, Procceding de SMW08, 27-29 octobre 2008, Florence, Italie

[8] Jean Charles Candoré, J.L Bodnar, Vincent Detalle, Philippe Grossel: Non destructive testing in situ, of works of art by stimulated infra-red thermography, Journal of physics conferences series, 214, (2010) 012068

[9]D. Maillet, S. André, J.C. Batsale, A. Degiovanni, C. Moyne, Thermal quadrupoles. Solving the heat equation through integral transforms, Wiley (2000)

[10]W Parker, Flash method of determining thermal diffusivity, J Appl. Phys, 32, (9), 1961, $1679-1684$

[11] A. Degiovanni, G. Sinicki and M. Laurent : Heat pulse thermal diffusivity measurements, thermal conducvity 18, New Ork, plenum press, 1984, pp 537-551 